\title{
Carfilzomib demonstrates broad anti-tumor activity in pre-clinical non-small cell and small cell lung cancer models
}

\author{
Amanda F Baker ${ }^{\text {** }}$, Neale T Hanke ${ }^{1}$, Barbara J Sands ${ }^{1}$, Liliana Carbajal ${ }^{1}$, Janet L Anderl ${ }^{2}$ and Linda L Garland ${ }^{1}$
}

\begin{abstract}
Background: Carfilzomib (CFZ) is a proteasome inhibitor that selectively and irreversibly binds to its target and has been approved in the US for treatment of relapsed and refractory multiple myeloma. Phase 1B studies of CFZ reported signals of clinical activity in solid tumors, including small cell lung cancer (SCLC). The aim of this study was to investigate the activity of CFZ in lung cancer models.
\end{abstract}

Methods: A diverse panel of human lung cancer cell lines and a SHP77 small cell lung cancer xenograft model were used to investigate the anti-tumor activity of CFZ.

Results: CFZ treatment inhibited both the constitutive proteasome and the immunoproteasome in lung cancer cell lines. CFZ had marked anti-proliferative activity in A549, H1993, H520, H460, and H1299 non-small cell lung cancer (NSCLC) cell lines, with $\mathrm{IC}_{50}$ values after 96 hour exposure from $<1.0 \mathrm{nM}$ to $36 \mathrm{nM}$. CFZ had more variable effects in the SHP77 and DMS114 SCLC cell lines, with IC 50 values at 96 hours from $<1 \mathrm{nM}$ to $203 \mathrm{nM}$. Western blot analysis of CFZ-treated H1993 and SHP77 cells showed cleavage of poly ADP ribose polymerase (PARP) and caspase-3, indicative of apoptosis, and induction of microtubule-associated protein-1 light chain-3B (LC3B), indicative of autophagy. In SHP77 flank xenograft tumors, CFZ monotherapy inhibited tumor growth and prolonged survival, while no additive or synergistic anti-tumor efficacy was observed for CFZ + cisplatin (CDDP).

Conclusions: CFZ demonstrated anti-proliferative activity in lung cancer cell lines in vitro and resulted in a significant survival advantage in mice with SHP77 SCLC xenografts, supporting further pre-clinical and clinical investigations of CFZ in NSCLC and SCLC.

Keywords: Carfilzomib, Proteasome inhibitor, Lung cancer, Cisplatin

\section{Background}

Over the last several decades, proteasome inhibition has been extensively investigated as a selective anti-cancer strategy and validated in clinical trials using first and second generation proteasome inhibitors (PIs) [1]. Inhibition of the proteasome can induce disturbances in signal transduction, apoptosis regulation, cell cycle control, transcriptional regulation, and inflammation [2]. A dominant mechanism of action that contributes to the anti-tumor activity of proteasome inhibition is the down-regulation of proto-oncogenic nuclear factor

\footnotetext{
* Correspondence: abaker@uacc.arizona.edu

'University of Arizona Cancer Center, College of Medicine, Section of Hematology/Oncology, 1515 N Campbell Ave, Tucson, AZ, USA Full list of author information is available at the end of the article
}

kappa B (NF-кB) signaling through the blocking of inhibitory factor kappa B (I-кB) degradation; inhibition of NF- $\mathrm{KB}$ signaling reduces expression of pro-inflammatory response genes and upregulates several cycle-dependent kinase inhibitors, promoting tumor cell apoptosis [3]. Other mechanisms by which proteasome inhibitors induce tumor cell apoptosis include phosphorylation and cleavage of the anti-apoptotic factor Bcl-2, stabilization of $\mathrm{p} 53$, interference with the unfolded protein response leading to endoplasmatic reticulum stress, and activation of TNF-related apoptosis-inducing ligand-induced apoptosis through increased death receptors DR4 and DR5 [4-7].

Inhibition of the proteasome has proven to be an effective therapeutic strategy for multiple myeloma and mantle cell lymphoma $[8,9]$. There has been interest in 
proteasome inhibition as a therapeutic strategy in solid tumors, including lung cancer. Bortezomib (BTZ), the first-in-class Food and Drug Administration approved PI, has been investigated in preclinical models and in clinical trials as an anti-cancer therapeutic for lung cancer. While BTZ showed potent in vitro activity in a wide range of non-small cell lung cancer (NSCLC) cell lines and demonstrated significant in vivo activity [10], clinical trials with BTZ monotherapy and in combination with chemotherapy or targeted agents in chemotherapy-naïve and previously-treated NSCLC patients yielded overall mixed results [11-18]. In the setting of relapsed/refractory small cell lung cancer (SCLC), a clinical trial of BTZ reported limited single-agent activity [19].

Carfilzomib (CFZ) is a selective PI that is approved in the United States for the treatment of relapsed and refractory multiple myeloma (RRMM). CFZ binds irreversibly to its target, resulting in sustained inhibition, which is in contrast to the reversible, boronate-based PIs, such as BTZ and MLN9708 [20-23]. CFZ selectively inhibits the chymotrypsin-like activity of the constitutive proteasome and the immunoproteasome [21,22]. CFZ, unlike BTZ, has minimal off-target effects on non-proteasome, serine proteases including cathepsin A, cathepsin G, chymase, dipeptidyl peptidase II, and HtrA2/Omi, which is thought to underlie its favorable toxicity profile with less neurotoxicity than BTZ [24]. CFZ overcomes BTZ resistance in some preclinical models, suggesting that selective, irreversible PIs without dose-limiting neurotoxicity may lead to more potent antitumor response and an improved tolerability profile compared with reversible PIs [25]. A phase I/II study of CFZ reported a durable partial tumor response in a patient with heavily pretreated SCLC [26]. Additionally, CFZ has shown clinical activity in some BTZ-treated patients [27,28].

While novel targeted therapy has proven effective in a subset of NSCLC patients, mainly never smokers, there are relatively limited therapeutic options after failure of first-line regimens for both NSCLC and SCLC related to intrinsic and acquired mechanisms of resistance to chemotherapy. There continues to be interest in developing novel molecularly targeted therapeutic strategies for lung cancer. Given the potential for improved efficacy and greater tolerability of CFZ, we investigated the anti-tumor activity of CFZ in NSCLC and SCLC cell line models alone and in combination with cisdiammineplatinum (II) dichloride (cisplatin, CDDP). We report that proteasome inhibition with CFZ resulted in potent in vitro growth inhibition and induction of apoptosis across a diverse set of lung cancer cell lines and in vivo tumor growth inhibition in a SCLC xenograft model. However, the combination of CFZ with CDDP was not additive or synergistic in a number of cell lines and a SCLC xenograft, suggesting that other rational combinations of CFZ with chemotherapy or targeted agents be investigated.

\section{Methods}

Reagents and antibodies

CFZ, provided by Onyx Pharmaceuticals, Inc., an Amgen subsidiary (South San Francisco, CA), was dissolved in dimethyl sulfoxide (DMSO) (Sigma-Aldrich, St. Louis, MO) at a stock concentration of $10 \mathrm{mM}$ and stored at $-20^{\circ} \mathrm{C}$. A stock concentration of $3.3 \mathrm{mM}$ CDDP in saline (Teva Pharmaceuticals, Israel) was stored at $-20^{\circ} \mathrm{C}$. Antibodies against poly ADP ribose polymerase (PARP), cleaved caspase-3, p-glycoprotein (Pgp; MDR1), and B-cell lymphoma 2 (Bcl-2) were purchased from Cell Signaling Technology (Beverly, MA). Antibodies against microtubule-associated protein-1 light chain-3B (LC3B) were obtained from Sigma-Aldrich. Alpha-tubulin antibodies were purchased from Calbiochem (La Jolla, CA). The secondary antibodies, HRP-conjugated goat antirabbit and HRP-conjugated goat anti-mouse, were purchased from Jackson ImmunoResearch (West Grove, PA).

\section{Cell lines}

All NSCLC (NCI-H520, A549, NCI-H1993, NCI-H460, and NCI-H1299) and SCLC (SHP77 and DMS114) cell lines were obtained from the American Tissue and Cell Collection (ATCC). These cells represent different pathological subtypes (squamous, adenocarcinoma, carcinoma) with SCLC cells derived from both metastatic lesions (SHP77) and a primary tumor (DMS114). A variety of molecular characteristics are also represented including wild-type p53 (H549, H460), reduced or deleted p53 (H520, H1299), wild-type KRAS (H1299), mutated KRAS (A549, H460), wild-type EGFR (A549), mutated EGFR (H1993, H460), and amplified c-met (H1993). All cells were cultured in RPMI 1640 (Cellgro) with 10\% fetal bovine serum (FBS), $1 \mathrm{mM}$ sodium pyruvate, and 10 mM HEPES. SHP77 cells were maintained in a similar manner except that heat-inactivated FBS was used. All cells were grown in $5 \% \mathrm{CO}_{2}$ at $37^{\circ} \mathrm{C}$ in a humidified tissue culture incubator. Cells were routinely tested for mycoplasma contamination using a MycoAlert mycoplasma detection kit (Lonza, Rockland, ME) and were found to be negative. To verify cell line authenticity, genomic DNA was extracted (Sigma GIN70-KT), diluted appropriately in TE buffer, and submitted to the University of Arizona Genomics Core (Human Origins Gentoyping Lab) for analysis. Autosomal short tandem repeat typing was conducted across the 13 core STRs in CODIS and referenced against allelic peaks in cell lines of previously confirmed genotype. All cell lines were verified as authentic. 


\section{Proliferation assay}

Cells were seeded in 96-well plates and incubated overnight. Cultures were exposed to various concentrations of CFZ or CDDP for the specified treatment intervals. Proliferation of adherent cells was determined by $3-[4,5-$ dimethylthiazol-2-yl]-2,5-diphenyltetrazolium bromide (MTT) assay. Proliferation of suspension cells was determined by 3-(4,5-dimethylthiazol-2-yl)-5-(3-carboxymethoxyphenyl)-2-(4-sulfophenyl)-2H-tetrazolium (MTS) assay. For adherent cultures, MTT dye $(2 \mathrm{mg} / \mathrm{ml})$ was added, and the cells were incubated for an additional 4 hours at $37^{\circ} \mathrm{C}$. After removal of medium, the resulting formazan crystals were dissolved in DMSO (SigmaAldrich) for 5 minutes and the plates were read in a spectrophotometer at $540 \mathrm{~nm}$. For suspension cultures, MTS dye $(0.37 \mathrm{mg} / \mathrm{mL})$ was added. The cells were incubated for 4 hours and then read spectrophotometrically at $490 \mathrm{~nm}$. Dose response curves were created using GraphPad Prism version 5.01 (GraphPad Software Inc, La Jolla, CA). $\mathrm{IC}_{50}$ values were calculated using CalcuSyn (Biosoft, Great Shelford, Cambridge, UK).

\section{Proteasome subunit quantification}

The proteasome constitutive/immunoproteasome subunit enzyme-linked immunosorbent (ProCISE) assay was used to quantitate individual constitutive $(\beta 5, \beta 1$, and $\beta 2$ ) and immunoproteasome (LMP7, LMP2, and MECL1) subunits [29]. Briefly, cell lysate was incubated with a biotinylated proteasome active-site binding probe (PABP). Lysate was then denatured, and subunits bound to PABP were isolated with streptavidin-conjugated sepharose beads. Individual subunits were probed with subunit-specific primary antibodies, followed by HRPconjugated secondary antibodies. A chemiluminescent substrate was used to generate a luminescent signal associated with bound HRP, which was read on a luminometer. Absolute values of subunit per microgram of total protein were determined based on a purified proteasome standard curve. Statistical significance was determined by Student's t test.

\section{Cell viability}

Cells were seeded in 6-well plates and incubated overnight. Cultures were left untreated or treated with predetermined $\mathrm{IC}_{50}$ doses of $\mathrm{CFZ}$ or CDDP and incubated for an additional 48, 72, or 96 hours. After each time point, the media containing any non-adherent cells was collected. Adherent cells were then detached using trypsin, suspended in culture medium, and disaggregated by manual pipetting. After mixing all collected cells with trypan blue (Thermo Scientific), viable cells that excluded the dye and dead cells that stained an intense blue were counted using a hemocytometer.

\section{Western blot analysis}

After various time points, the cells were rinsed with cold phosphate buffered saline (PBS) and harvested in a buffer containing $50 \mathrm{mM}$ Tris $\mathrm{HCl}(\mathrm{pH} 8.0), 150 \mathrm{mM} \mathrm{NaCl}$, $1 \%$ Triton X-100, 2 mM EDTA, $5 \mathrm{mM} \mathrm{Na}_{3} \mathrm{VO}_{4}, 200 \mu \mathrm{M}$ $\mathrm{NaF}, 21 \mu \mathrm{M}$ leupeptin, $230 \mathrm{nM}$ aprotinin, and $1 \mathrm{mM}$ phenylmethylsulfonyl fluoride (PMSF). The cell lysate was sonicated and centrifuged at $10,000 \times g$ for $10 \mathrm{~min}$ at $4^{\circ} \mathrm{C}$. Protein concentration of the resulting supernatant was determined using a $660 \mathrm{~nm}$ Protein Assay kit (Thermo Scientific, Rockford, IL). Twenty micrograms of total cell lysate were boiled for $5 \mathrm{~min}$ and resolved in a $10 \%$ acrylamide/bisacrylamide gel by electrophoresis at $125 \mathrm{~V}$ for $105 \mathrm{~min}$. Proteins were then transferred to a polyvinylidene fluoride (PVDF) membrane (Millipore, Billerica, MA). Membranes were blocked with $5 \%$ milk in Tris-buffered saline containing $0.1 \%$ Tween-20 (TBST) for $30 \mathrm{~min}$ before overnight incubation at $4{ }^{\circ} \mathrm{C}$ with various primary antibodies, typically at a 1:1000 dilution. Blots were rinsed with TBST and incubated for 2 hours at room temperature with secondary antibody at a 1:15,000 dilution. Reactive bands were visualized by exposure to film using Pierce Supersignal West Pico HRP Detection Reagent (Thermo Fisher Scientific, Rockford IL). Blots were stripped in $0.2 \mathrm{M} \mathrm{NaOH}$ with shaking for $10 \mathrm{~min}$ at room temperature and then re-probed for loading control.

\section{Drug combination studies}

Cells were seeded as described in the proliferation assay section and treated with various concentrations of CFZ and CDDP either simultaneously, CDDP followed by CFZ, or CFZ followed by CDDP. Simultaneously-treated cells were incubated for 96 hours before being analyzed. For CDDP/CFZ, cells were treated with CDDP for 24 hours, followed by CFZ for an additional 72 hours before analysis. For CFZ/CDDP, cells were first treated with CFZ for 48 hours, then with CDDP for an additional 48 hours before analysis. For sequential drug treatments, the first drug remained in the media as the second drug was added. The range of concentrations used for each drug was $4.5 \mathrm{nM}$ to $30 \mu \mathrm{M}$. The upper dose $(30 \mu \mathrm{M})$ is near the estimated blood concentration of CDDP found in patients following administration of the dosage that is used clinically $\left(100 \mathrm{mg} / \mathrm{m}^{2}\right)$ [30]. Interactions between CFZ and CDDP were analyzed using the median effect method of Chou and Talalay [31]. In this method, dose-response curves are generated for each agent individually. These results are then used to analyze the results obtained from the combination treatment. A combination index $(\mathrm{CI})$ was generated using CalcuSyn software (Biosoft, Cambridge, United Kingdom) and synergy level classifications were assigned as described in the CalcuSyn manual. A CI of less than 1 
indicates synergy $(<0.3$, strong synergy), a $\mathrm{CI}$ of 1 indicates additive effects, and a CI of more than 1 is indicative of antagonistic effects ( $>3$, strong antagonism).

\section{In vivo SHP77 xenograft studies}

Studies were performed under approved protocols in accordance with Institutional Animal Care and Utilization Committee guidelines. SHP77 $\left(10^{7}\right)$ cells were subcutaneously injected into flanks of female scid mice. When tumors became palpable (average tumor volume between $200-300 \mathrm{~mm}^{3}$ ), mice were randomized into four treatment groups: 1) Control - vehicle only, 2) CFZ $3 \mathrm{mg} / \mathrm{kg}$ intravenous (IV) injection for two consecutive days for the first week followed by $5 \mathrm{mg} / \mathrm{kg}$ IV for two consecutive days repeated weekly until death or sacrifice, 3) $\mathrm{CDDP}-4 \mathrm{mg} / \mathrm{kg}$ intraperitoneal (IP) injection once per week for 3 weeks, and 4) CFZ - $5 \mathrm{mg} / \mathrm{kg} \mathrm{IV}+$ CDDP $-4 \mathrm{mg} / \mathrm{kg}$ IP. For combination treatment, CFZ (3 $\mathrm{mg} / \mathrm{kg}$ the first week and $5 \mathrm{mg} / \mathrm{kg}$ on subsequent weeks) was given on days 1 and 2 of each week and CDDP was given on day 5 for 3 weeks. Animals were euthanized when tumors reached $2000 \mathrm{~mm}^{3}$ or became necrotic. A separate group of mice bearing SHP77 flank xenografts $\left(200-500 \mathrm{~mm}^{3}\right)$ were randomized into a vehicle control group or CFZ (5 mg/kg IV) dose group $(\mathrm{N}=4)$ and treated for two consecutive days. 48 hours later, mice were euthanized and tumors were removed and fixed in $10 \%$ buffered formalin for pharmacodynamic biomarker analysis.

\section{Histology and immunohistochemistry}

SHP77 flank xenograft tumors were excised and immediately fixed in 10\% PBS buffered formalin. Tissues were transferred to $70 \%$ ethanol within 24 hours and embedded in paraffin within 3 days. Sectioned tissue sections (0.3 micron slices) were prepared for hematoxylin and eosin (H\&E) staining or immunohistochemistry (IHC) from formalin fixed, paraffin embedded (FFPE) blocks. IHC was performed using cleaved caspase- 3 antibody (\#9661, Cell Signaling, Danvers, MA) diluted 1:400. Tissue sections were stained on a Discovery XT automated system (Ventana Medical Systems, Inc, Tucson, Arizona) using proprietary reagents. Cleaved caspase- 3 was detected using the Ventana Anti-Rabbit Secondary Antibody for 16 minutes. Labeling was visualized with the Ventana OmniMap kit followed by counterstaining with hematoxylin. Slides were then dehydrated and coverslips were added as per normal laboratory protocol. Images were acquired using an Olympus BX50 microscope and an Olympus DP72 digital camera with CellSens Digital Image software. One pathologist (Dr. Raymond Nagle, University of Arizona Cancer Center) evaluated each slide and scored the percentage of cells staining positive.

\section{Results}

CFZ suppresses proliferation in a range of NSCLC and SCLC cell lines

A panel of 7 cell lines was used to model the anti-tumor effects of CFZ treatment in lung cancer. We sought to determine the in vitro profile of CFZ sensitivity in these cells as compared to CDDP, a platinum-based compound commonly used in lung cancer treatment regimens. MTT or MTS assays were performed on cell lines following 48 or 72 hour treatments. Results from one representative experiment $(n=6)$ are shown in Figure 1 . In each of the cell lines tested, CFZ was more potent than CDDP in inhibiting cell growth. Only slight inhibitory effects were seen at 24 hours, and growth curves at 96 hours were similar to the 72-hour curves (data not shown). $\mathrm{IC}_{50}$ values were calculated from the 48,72 , and 96-hour growth curves (Table 1 ). The $\mathrm{IC}_{50}$ values for cell lines treated with CFZ were in the low nanomolar range. In contrast, the $\mathrm{IC}_{50}$ values for CDDP treated cells lines were in the micromolar range. CFZ maximal growth inhibition improved over time, reflected by a decreasing $\mathrm{IC}_{50}$, for all cell lines with the exception of SHP77 cells, which showed a $60 \%$ increase in the $\mathrm{IC}_{50}$ value between 48 and 72 hour treatments.

\section{CFZ inhibits proteasome subunits in lung cancer cell lines}

The ProCISE assay was used to determine which proteasome subunits are inhibited by CFZ in lung cancer cell lines. This immunosorbent assay-based method provides accurate quantitation of proteasome subunits within cell lysate [29]. The abundance of the chymotrypsin-like (CT-L), caspase-like (C-L), and trypsin-like (T-L) subunits of both the constitutive and immunoproteasome was quantified in various NSCLC and SCLC cell lines. Similar to results reported with other cell types [29], CFZ selectively inhibits the CT-L activity of the proteasome in multiple lung cancer cell lines. The activities of the $\beta 5$ subunit of the constitutive proteasome and the LMP7 subunit of the immunoproteasome were significantly reduced in both the H1993 (NSCLC) and SHP77 (SCLC) cell lines when treated with the predetermined $\mathrm{IC}_{50}$ doses of CFZ for 48 hours (Figure 2). Another NSCLC cell line (A549) was tested with similar results (data not shown).

\section{CFZ reduces cell viability while inducing apoptosis and autophagy}

To determine the cytotoxic effects of CFZ in lung cancer cell lines, the H1993 NSCLC and SHP77 SCLC cells were treated with predetermined 48 hour $\mathrm{IC}_{50}$ doses. Cells were collected at 48, 72, and 96 hour time points and analyzed for viability (Figure 3A). Results demonstrate a strong sensitivity to CFZ in vitro with a $40-60 \%$ decrease in viable cells. This is similar to CDDP 


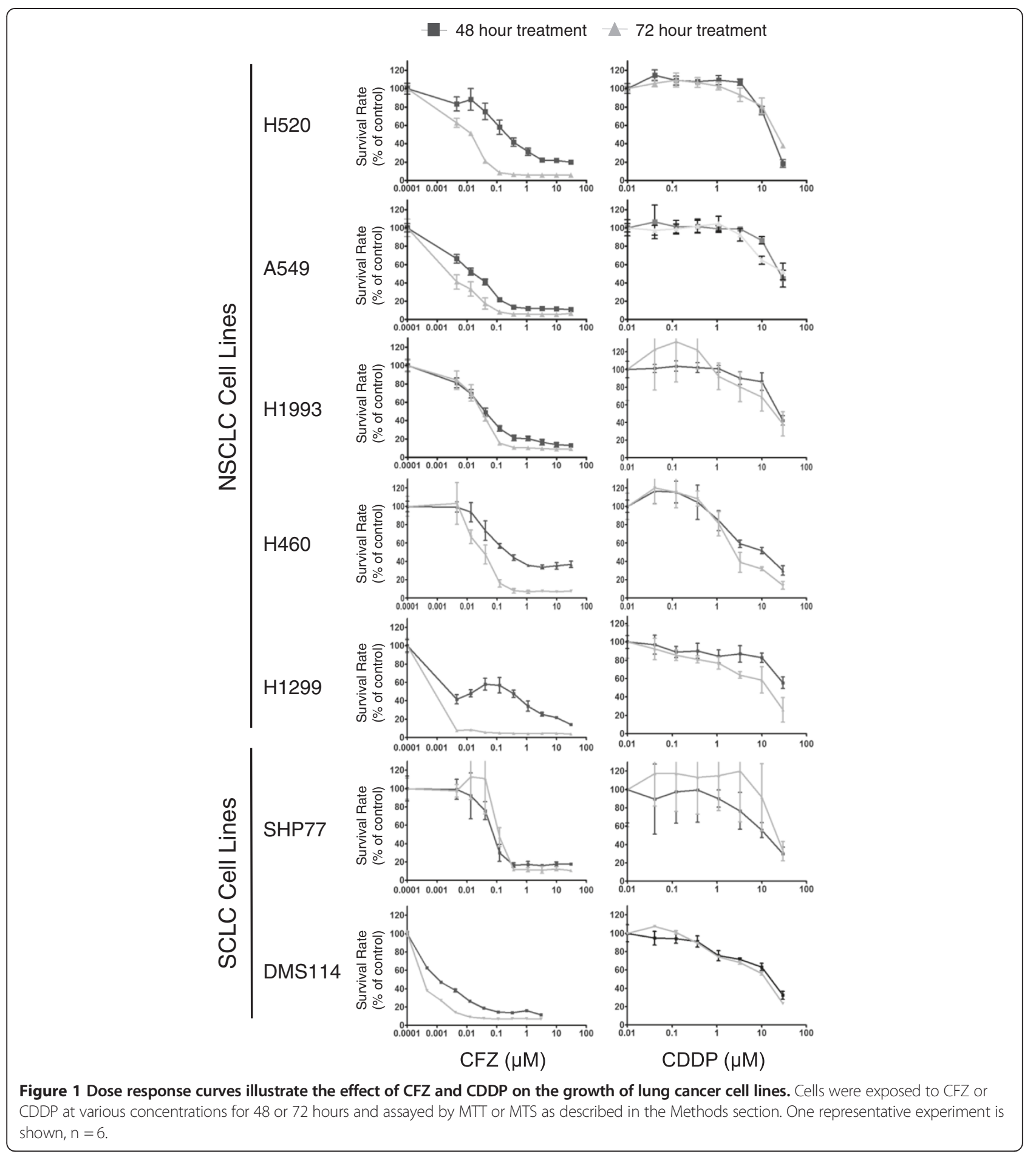

treatment which showed a 30-60\% decrease in viability. To determine whether the observed reduction in viability with CFZ treatment occurred via the induction of apoptosis, levels of cleaved PARP and cleaved caspase-3 were evaluated by Western blot. As with CDDP, treatment with CFZ showed induction of these apoptotic markers (Figure 3B).
Some studies suggest that one possible mechanism of resistance to proteasome inhibition is induced autophagic flux [32]. To profile autophagy in our lung cancer cells we examined LC3B which is present in its cytoplasmic form (LC3B-I) or is directly associated with the plasma membrane of autophagosomes (LC3B-II). We noted increased LC3B-II, a marker of autophagy, at 24, 
Table 1 Sensitivity of lung cancer cell lines to CFZ and CDDP

\begin{tabular}{|c|c|c|c|c|c|c|}
\hline \multirow{2}{*}{ Cell line } & \multicolumn{3}{|c|}{ CFZ IC ${ }_{50}(\mu \mathrm{M})$} & \multicolumn{3}{|c|}{$\mathrm{CDDP} \mathrm{IC} \mathrm{C}_{50}(\mu \mathrm{M})$} \\
\hline & $48 \mathrm{~h}$ & $72 \mathrm{~h}$ & $96 \mathrm{~h}$ & $48 \mathrm{~h}$ & $72 \mathrm{~h}$ & $96 \mathrm{~h}$ \\
\hline \multicolumn{7}{|l|}{ NSCLC } \\
\hline H520 & 0.0769 & 0.0299 & 0.0083 & 19.43 & 23.24 & 18.15 \\
\hline A549 & 0.0901 & 0.0716 & 0.0047 & 25.97 & 26.53 & 9.01 \\
\hline H1993 & 0.0277 & 0.0172 & 0.0216 & 29.60 & 19.58 & 15.52 \\
\hline $\mathrm{H} 460$ & 0.1657 & 0.0631 & 0.0364 & 9.02 & 3.72 & 2.69 \\
\hline H1299 & 0.0500 & 0.0293 & $<0.0001$ & $>30.0$ & 8.81 & 3.53 \\
\hline \multicolumn{7}{|l|}{ SCLC } \\
\hline SHP77 & 0.0614 & 0.0994 & 0.2031 & 12.17 & 21.55 & 28.57 \\
\hline DMS114 & 0.0007 & 0.0002 & $<0.0001$ & 13.13 & 8.10 & 3.47 \\
\hline
\end{tabular}

The determined inhibitory concentrations (IC 50 values) represent the level of drug that inhibited cell growth by $50 \%$. IC 50 values ( $\mu \mathrm{M})$ of $\mathrm{CFZ}$ at 48 and 72 hours are the mean of two or more independent experiments, $n \geq 12$. Other $I C_{50}$ values are the mean of one experiment, $n=6$.

48, and 96 hours in most cell lines tested (Figure 3C and data not shown). A larger increase in LC3B-II was found in the more CFZ-resistant SHP77 cell line as compared to the more CFZ-sensitive H1993 cell line.

Effects of combining CFZ and CDDP in lung cancer cell lines Because CDDP is frequently used as part of standard front-line chemotherapy regimens in NSCLC and SCLC, we investigated the combined activity of CFZ and CDDP when added simultaneously for 96 hours on inhibition of cell proliferation using the MTT or MTS assay (Table 2). This combination had mixed results, with antagonism observed in $\mathrm{H} 520$ and H1993 cell lines and modest synergy observed in the H460 and SHP77 cell lines. Cell characteristics, such as mutations of EGFR or K-Ras, may alter the effectiveness of first-line platinumbased chemotherapy [33]. To investigate whether sequential administration of agents could improve activity, we treated with CDDP for 24 hours, followed by addition of CFZ for 72 hours, or CFZ for 48 hours followed by addition of CDDP for 48 hours. The first drug remained in the media as the second drug was added. Results were similar regardless of sequence, with antagonism (decrease in efficacy) observed in all cell lines except the H460 cells when CFZ was administered first; in SHP77 cells there was synergy observed regardless of sequencing. Synergy values were not calculated in the H1299 or DMS114 cell lines due to the almost complete inhibition of proliferation observed from combination treatments.

\section{In vivo growth inhibition and survival}

Groups of scid mice $(\mathrm{n}=8)$ were used to evaluate in vivo tumor responses to CFZ. Treatment with CFZ monotherapy resulted in tumor growth delay and a significant survival advantage in mice bearing flank SHP77 tumors (Figure 4A,B). Treatment with monotherapy CDDP caused a tumor growth delay, but failed to show a significant survival advantage (Figure 4A,C). Similarly, the combination of CFZ and CDDP demonstrated a tumor growth delay, but no significant survival advantage (Figure 4A, D). It should be noted that the dose of CDDP used was modest in order to minimize toxicity when both drugs were combined. Notably, two mice

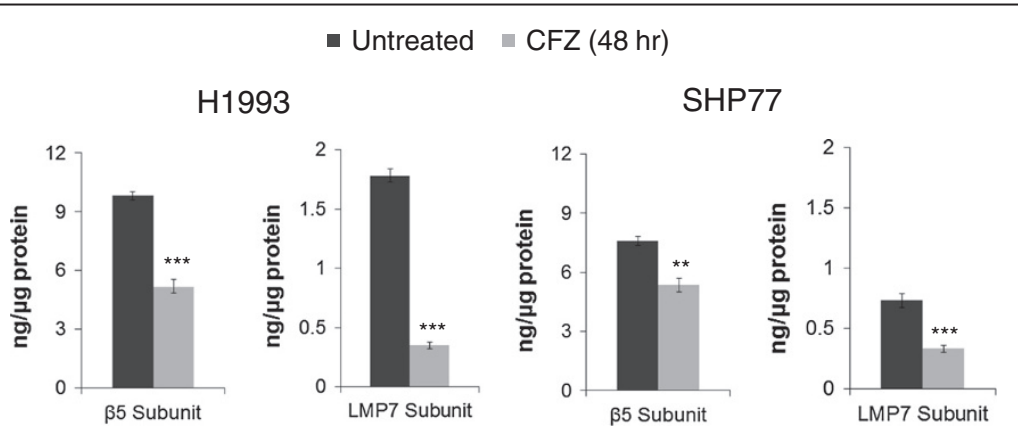

Figure 2 The c20S subunit $\beta 5$ and the i20S subunit LMP7 are inhibited in CFZ treated H1993 and SHP77 cells. Cells left untreated or treated for 48 hours with CFZ (48 hour IC 50 dosage) were evaluated using the ProCISE assay to determine the level of uninhibited subunits. Mean \pm SD are from three pseudo-replicates. Results were statistically significant $\left({ }^{* * *} p<0.001,{ }^{* *} p<0.01\right)$ using Student's t-test. 


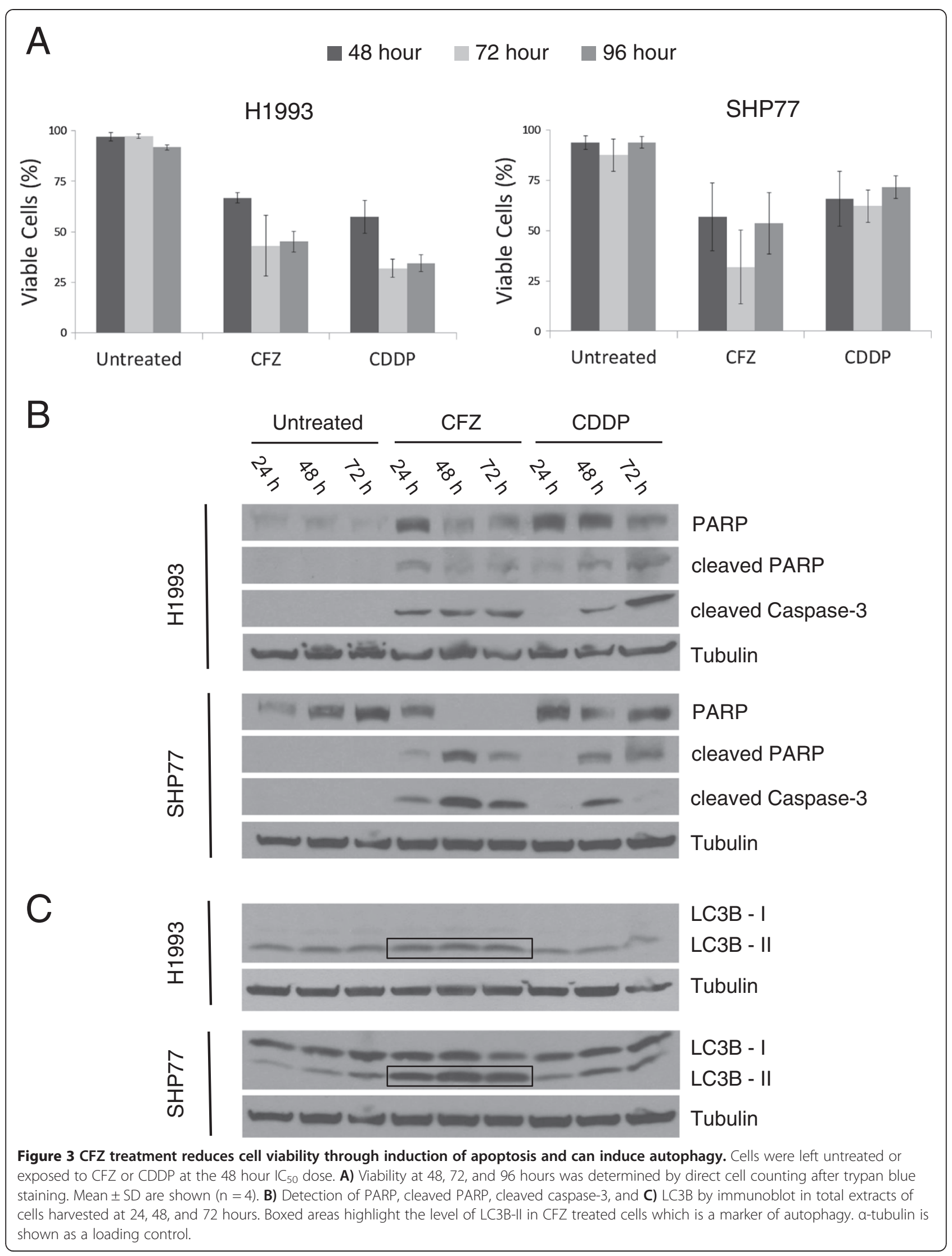


Table 2 Inhibitory activity of CFZ combined with CDDP in lung cancer cell lines

\begin{tabular}{|c|c|c|c|c|c|c|}
\hline \multirow{2}{*}{ Cell line } & \multicolumn{2}{|c|}{ Simultaneous } & \multicolumn{2}{|c|}{$\mathrm{CDDP} \rightarrow \mathrm{CFZ}$} & \multicolumn{2}{|c|}{$\mathrm{CDDP} \rightarrow \mathrm{CFZ}$} \\
\hline & $\mathrm{IC}_{50}(\mathrm{nM})$ & Synergy Value & $I C_{50}(n M)$ & Synergy Value & $\mathrm{IC}_{50}(\mathrm{nM})$ & Synergy Value \\
\hline \multicolumn{7}{|l|}{ NSCLC } \\
\hline H520 & 14.5 & Ant. & 427.3 & Ant. + & 87.6 & Ant. + \\
\hline A549 & $<1$ & NC & 206.2 & Ant. + & 72.3 & Ant. + \\
\hline H1993 & 173.1 & Ant. + & 134.0 & Ant. + & 200.6 & Ant. + \\
\hline $\mathrm{H} 460$ & 14.8 & Syn. & 258.3 & Ant. + & 25.1 & Syn. \\
\hline H1299 & $<1$ & $\mathrm{NC}$ & $<1$ & NC & $<1$ & NC \\
\hline \multicolumn{7}{|l|}{ SCLC } \\
\hline SHP77 & 72.8 & Syn. & 171.8 & Syn. & 21.7 & Syn. + \\
\hline DMS114 & $<1$ & NC & $<1$ & NC & $<1$ & NC \\
\hline
\end{tabular}

Cells were treated with equivalent doses of CFZ and CDDP either simultaneously, CDDP followed by CFZ, or CFZ followed by CDDP and evaluated 96 hours after initial treatment. $I C_{50}$ values represent the concentration at which the drug combination inhibited cell growth by $50 \%$. Synergy values were determined with Calcusyn software from the combination index (Cl) method described by Chou and Talalay [31]. Cl interpretation: $<0.3$ strong synergism (Syn. +), $0.3-0.9$ synergism (Syn.), 1-3 antagonism (Ant.), >3 strong antagonism (Ant. +), or not calculated due to high cell death at lowest dose (NC).

died within the first week of combination CFZ and CDDP treatment, with deaths being judged to be likely drug-related. Due to the potency observed with CFZ treatment in the DMS114 cell line, we attempted to grow this cell line as flank xenografts in scid mice to investigate CFZ in vivo efficacy in this model. Unfortunately, we were not able to observe any palpable tumors up to 60 days post-cell inoculation. To determine if CFZ was inducing apoptosis in vivo, we analyzed activation and cleavage of caspase-3 in SHP77 xenograft tumors (Figure 4E). A pathologist score showed a significant increase in cleaved caspase- 3 in the CFZ treated xenografts versus the vehicle treated xenografts.

\section{Conclusions}

Pre-clinical studies with the first generation reversible proteasome inhibitor BTZ showed that BTZ caused proteasome inhibition that was associated with diminished cell proliferation and increased cell death across a wide variety of NSCLC models [13]. Similarly, we found that CFZ inhibits cell proliferation and induces apoptotic markers in a pathologically and molecularly diverse panel of lung cancer models, including SCLC. $\mathrm{IC}_{50}$ values for the cell lines treated with CFZ were all in the low nanomolar range (Table 1$)$. This is similar to the reported BTZ $\mathrm{IC}_{50}$ values $(30-62.5 \mathrm{nM})$ found in many of these cell lines $[3,34]$.

In vitro testing revealed differences between the SHP77 cells and the other cell lines tested. While the CFZ $\mathrm{IC}_{50}$ value decreased over time for all other cell lines tested, the $\mathrm{IC}_{50}$ value increased over time for the SHP77 cells, suggesting upregulation of a resistance mechanism or selection of an intrinsically resistant population of cells (Table 2). One explanation for this observation could be the expression of P-glycoprotein (Pgp, MDR1), a drug efflux pump recognized as a major chemotherapy resistance mechanism [35]. Unlike BTZ [36], CFZ has been reported to be a substrate for Pgp [37] and resistance may therefore be mediated by Pgp expression. The SHP77 cells grown in vitro express high levels of Pgp as compared to the other cell lines tested (Additional file 1: Figure S1). However, no change in Pgp expression was observed for CFZ treated SHP77 cells over a 96 hour period (data not shown). Therefore the SHP77 resistance mechanism(s) responsible for the increasing $\mathrm{IC}_{50}$ value over time for $\mathrm{CFZ}$ monotherapy remains unidentified.

We further investigated the efficacy of CFZ using the SHP77 cells in a xenograft model. Because synergy was observed during CFZ and CDDP treatment in the SHP77 cells (Table 2), we investigated both monotherapy and combined activity with CDDP in vivo. In spite of Pgp expression in the SHP77 cells, in vivo treatment resulted in tumor growth inhibition and a significant survival advantage (Figure 4). This coincided with increased cleaved caspase-3 found in xenograft tumor cells. Unlike in vitro where synergistic activity with CDDP was observed, the combination of CFZ and CDDP in vivo did not result in additive growth inhibition or a survival advantage over CFZ monotherapy. It is possible that the in vivo tumor microenvironment, which has different levels of growth factors and oxygen supply than cell culture may abrogate cisplatin efficacy and therefore not yield similar results to in vitro studies. Clinically, resistance to cisplatin is common in SCLC.

The lack of additive activity with CFZ and CDDP may be due to activation of survival signaling in response to CDDP and/or CFZ. There are multiple mechanisms by which cells acquire resistance to CDDP (reviewed by Galluzzi et al. [38]). Upregulation of heat shock proteins, which has been previously reported in response to proteasome inhibition, is associated with cisplatin resistance 


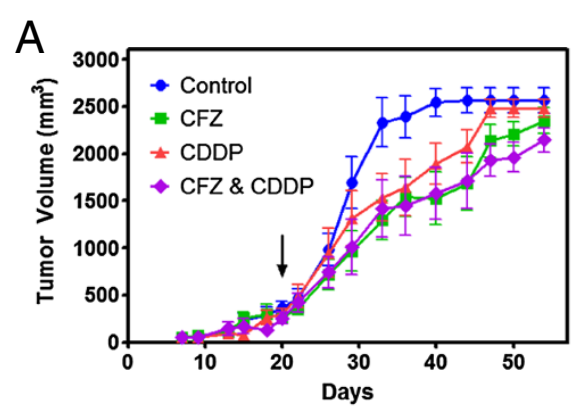

C

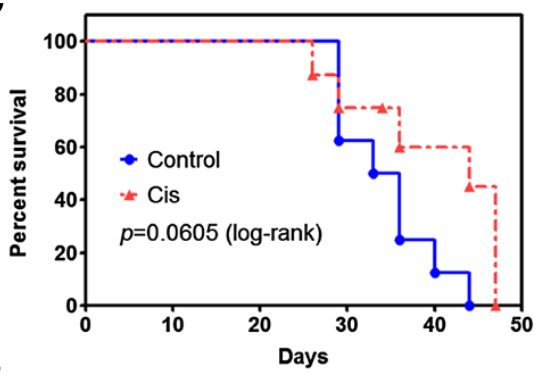

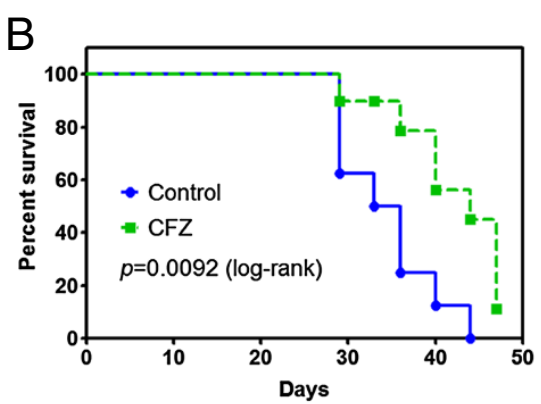

D

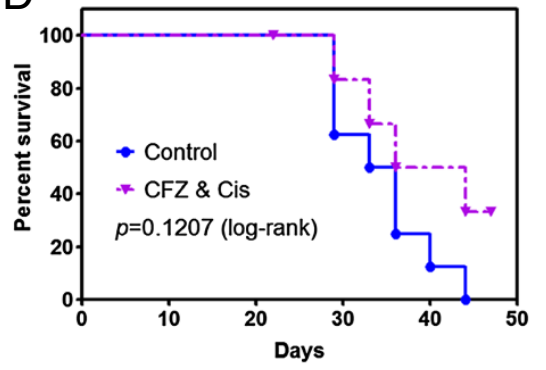

E

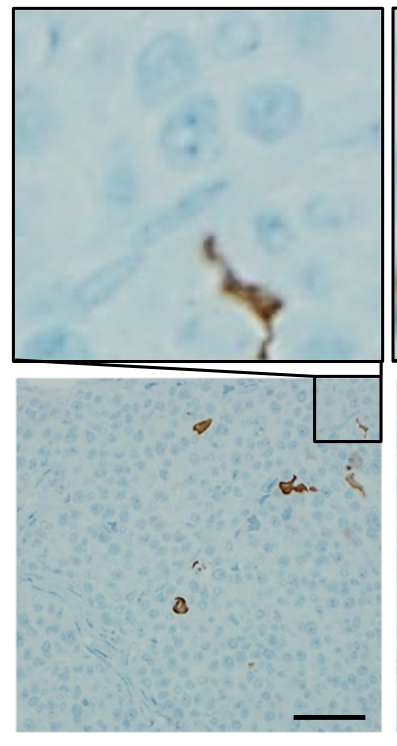

Vehicle
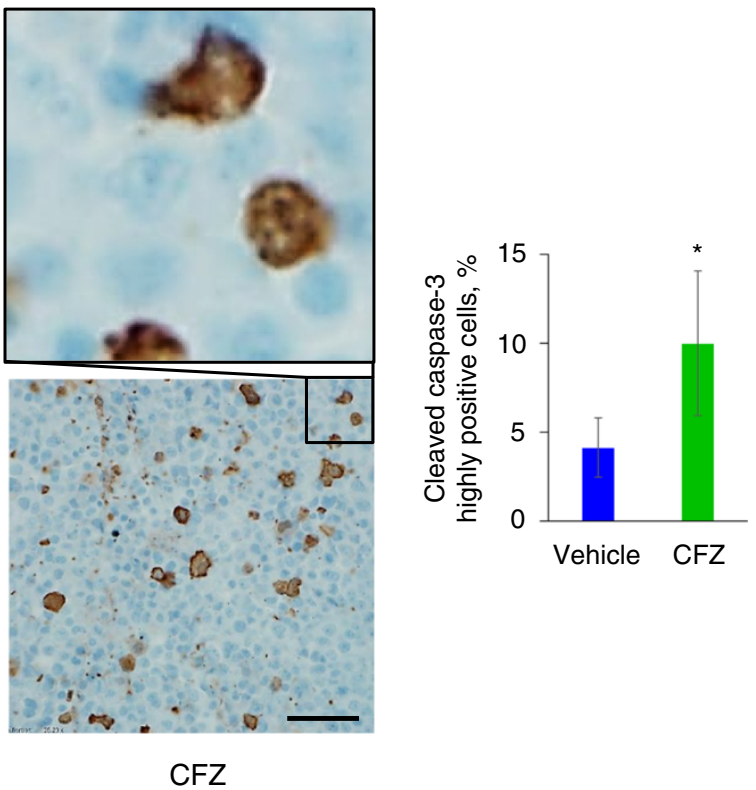

Figure 4 In vivo responses of SHP77 xenografts to CFZ and CDDP. Groups of scid mice $(n=8)$ were treated as detailed in the Methods section. (A) Mean tumor growth curves of SHP77 xenografts. The x-axis depicts days post tumor cell injection. Drug treatment was initiated on day 20 as indicated by arrow. (B, C, D) Kaplan-Meier survival curves of SHP77 tumor bearing mice for control and CFZ treated, control and CDDP treated, and control and CFZ/CDDP combination treated groups. The log-rank (Mantel-Cox) test was performed to evaluate the differences in survival between groups. A significant difference $(p<0.05)$ in survival was found between the control and CFZ treated groups. (E) SHP77 xenograft groups $(n=4)$ were treated two consecutive days with either vehicle or CFZ $(5 \mathrm{mg} / \mathrm{kg})$. Tumors were harvested 48 hours after the second dose and fixed sections were processed for immunohistochemical analysis. Representative photographs of immunoreactivity for cleaved caspase-3 at magnification of $60 \times$ and $400 \times$ are shown. Scale bar on $400 \times$ images $=50 \mu \mathrm{m}$. The percent of cells with cleaved caspase-3 is significantly higher in the CFZ treated tumors versus the vehicle treated tumors ( ${ }^{*} p<0.05$ using Student's t-test).

in ovarian cancer cells [39]. Autophagy has also been shown to be associated with acquired cisplatin resistance in the A549 NSCLC cell line [40]. We saw increased expression of LC3B-II, a putative marker of autophagy, in response to both CFZ and CDDP treatment in vitro in the SHP77 and H1993 cell lines (Figure 3C). This observation suggests that induction of autophagy by CFZ could contribute to the abrogated efficacy of CDDP.

Gaining a greater understanding of resistance mechanisms to proteasome inhibition will be important in further developing CFZ as a lung cancer therapeutic. 
Mechanisms for both intrinsic and acquired resistance to BTZ have been described [41-43]. In lung cancer cell lines, cross resistance to BTZ and CFZ has been observed in A549 and SW1753 cells, but not in H460 BTZ resistant cells. In these studies, resistance to BTZ was associated with mutant $\beta$-subunits within the proteasome core [41]. Resistance to BTZ has also been associated with basal proteasome levels [41]. We did not observe this trend when comparing the basal $\beta 5$ and LMP7 subunit levels with the corresponding CFZ $\mathrm{IC}_{50}$ values of the H1993 and SHP77 cell lines (Figure 1, Table 1) or with the A549 cells (data not shown).

Bcl-2 over-expression in SCLC has been linked with chemotherapy resistance [44]. Bortezomib has been shown to reduce $\mathrm{Bcl}-2$ levels and induce apoptosis in the H526 SCLC cell line [45]. In the A549 spheroid model, $\mathrm{Bcl}-2$ upregulation has been associated with BTZ resistance [46]. In head and neck cancer models CFZ resistance was associated with increased levels of the Bcl-2 family member, Mcl-1 [47]. When CFZ is combined with obatoclax, a pan-BH3 mimetic that inhibits Mcl-1, enhanced apoptosis is observed in diffuse large B-cell lymphoma cell lines [48]. Although treatment with CFZ or CPPD did not significantly modulate Bcl-2 levels in the H1993 or SHP77 cells (Additional file 1: Figure S2), future studies should investigate the combined activity of CFZ with Bcl-2 and/or Mcl-1 inhibitors in lung cancer.

We did not directly compare the anti-proliferative activity of BTZ to CFZ in the current study. However, previous studies suggest that BTZ and CFZ have similar in vitro activity in lung cancer cell lines [41]. Because CFZ displays greater specificity and has a different pharmacokinetic profile than BTZ; CFZ may have different activity than BTZ in clinical lung cancer studies [49]. One of the major dose-limiting toxicities of BTZ is peripheral neuropathy (PN). CFZ use is associated with much lower new-onset PN [50], making it a more attractive agent in the clinic. CFZ, unlike BTZ, does not induce neurodegeneration in vitro, which may explain its lower rates of PN in clinical trials [24]. CFZ overcomes BTZ resistance, suggesting that selective, irreversible PIs without dose-limiting neurotoxicity may lead to more potent antitumor response and an improved tolerability profile compared with reversible PIs [25].

Single-agent CFZ has been approved in the US for treatment of RRMM based on its efficacy and lack of cumulative toxicities [27]. Our findings reported here support further investigation of CFZ in novel combinations with chemotherapy and targeted agents in SCLC and NSCLC pre-clinical models to help guide the clinical development of CFZ in lung cancer. In addition, further delineation of resistance mechanisms to proteasome inhibition may aid in selection of lung cancer patients for CFZ-based therapy.

\section{Additional file}

Additional file 1: Figure S1. Relative Pgp expression in lung cancer cell lines. Total cell lysate from untreated cells were probed for expression of Pgp. The blot was reprobed for a-tubulin as a loading control. Figure S2. Analysis of Bcl-2 expression in H1993 and SHP77 cells. Cells were left untreated or exposed to CFZ or CDDP at the 48 hour $I C_{50}$ dose. Levels of $\mathrm{BCl}-2$ were determined by immunoblot in total extracts of cells harvested at 24,48 , and 72 hours. a-tubulin is shown as a loading control.

\section{Abbreviations}

Bcl-2: B-cell lymphoma 2; BTZ: Bortezomib; CDDP: Cisplatin or cisdiamminedichloroplatinum(II); CFZ: Carfilzomib; Cl: Combination index; I-kB: Inhibitory factor kappa B; LC3B: Microtubule-associated protein-1 light chain-3B; NF-kB: Nuclear factor kappa B; NSCLC: Non-small cell lung cancer; PARP: Poly ADP ribose polymerase; Pgp: P-glycoprotein; PIs: Proteasome inhibitors; PN: Peripheral neuropathy; RRMM: Relapsed and refractory multiple myeloma; SCLC: Small cell lung cancer.

\section{Competing interests}

JA is employed by Onyx Pharmaceuticals, Inc., an Amgen subsidiary.

\section{Authors' contributions}

AFB and LLG designed and supervised the study. Acquisition and analysis of data was performed by AFB, NTH, BJS, LC, and JLA. The manuscript was written by AFB, NTH and LLG. All authors read and approved the final manuscript.

\section{Acknowledgements}

This work was supported by a generous gift from the late Mrs. Jemmie Helmricks and her husband, a research collaboration award by Onyx Pharmaceuticals, Inc., an Amgen subsidiary (South San Francisco, CA), and a Basic/Clinical translational partnership pilot grant award from the Arizona Cancer Center Cancer Center Support Grant (PI Albers, David) P30CA02374-32 from the National Cancer Institute (NCI). The contents of this work are solely the responsibility of the authors and do not necessarily represent the official views of the NCl. The authors thank ET Chan and CJ Kirk of Onyx Pharmaceuticals for their assistance. The authors also thank the University of Arizona Cancer Center (UACC) experimental mouse shared services (EMSS), the UACC tissue acquisition and cellular/molecular analysis shared service (TACMASS), and the tissue core and image core facilities at the H. Lee Moffitt Cancer Center.

\section{Author details}

${ }^{1}$ University of Arizona Cancer Center, College of Medicine, Section of Hematology/Oncology, 1515 N Campbell Ave, Tucson, AZ, USA. Onyx Pharmaceuticals, Inc., an Amgen subsidiary, South San Francisco, CA, USA.

Received: 28 August 2014 Accepted: 11 December 2014 Published online: 31 December 2014

\section{References}

1. Zhang J, Wu P, Hu Y: Clinical and marketed proteasome inhibitors for cancer treatment. Curr Med Chem 2013, 20:2537-2551.

2. Moore BS, Eustaquio AS, McGlinchey RP: Advances in and applications of proteasome inhibitors. Curr Opin Chem Biol 2008, 12:434-440.

3. Ling $Y H$, Liebes L, Jiang JD, Holland JF, Elliott PJ, Adams J, Muggia FM, Perez-Soler R: Mechanisms of proteasome inhibitor PS-341-induced G(2)M-phase arrest and apoptosis in human non-small cell lung cancer cell lines. Clin Cancer Res 2003, 9:1145-1154.

4. Hoeller D, Dikic I: Targeting the ubiquitin system in cancer therapy. Nature 2009, 458:438-444.

5. Lee AH, Iwakoshi NN, Anderson KC, Glimcher LH: Proteasome inhibitors disrupt the unfolded protein response in myeloma cells. Proc Natl Acad Sci U S A 2003, 100:9946-9951.

6. Ludwig H, Khayat D, Giaccone G, Facon T: Proteasome inhibition and its clinical prospects in the treatment of hematologic and solid malignancies. Cancer 2005, 104:1794-1807.

7. Zhang HG, Wang J, Yang X, Hsu HC, Mountz JD: Regulation of apoptosis proteins in cancer cells by ubiquitin. Oncogene 2004, 23:2009-2015.

8. Hideshima T, Richardson P, Chauhan D, Palombella VJ, Elliott PJ, Adams J, Anderson KC: The proteasome inhibitor PS-341 inhibits growth, induces 
apoptosis, and overcomes drug resistance in human multiple myeloma cells. Cancer Res 2001, 61:3071-3076.

9. O'Connor OA, Wright J, Moskowitz C, Muzzy J, MacGregor-Cortelli B, Stubblefield M, Straus D, Portlock C, Hamlin P, Choi E, Dumetrescu O, Esseltine D, Trehu E, Adams J, Schenkein D, Zelenetz AD: Phase II clinical experience with the novel proteasome inhibitor bortezomib in patients with indolent non-Hodgkin's lymphoma and mantle cell lymphoma. J Clin Oncol 2005, 23:676-684.

10. Morgillo F, D'Aiuto E, Troiani T, Martinelli E, Cascone T, De PR, Orditura M, De VF, Ciardiello F: Antitumor activity of bortezomib in human cancer cells with acquired resistance to anti-epidermal growth factor receptor tyrosine kinase inhibitors. Lung Cancer 2011, 71:283-290

11. Davies AM, Chansky K, Lara PN Jr, Gumerlock PH, Crowley J, Albain KS, Vogel SJ, Gandara DR: Bortezomib plus gemcitabine/carboplatin as first-line treatment of advanced non-small cell lung cancer: a phase II Southwest Oncology Group Study (S0339). J Thorac Oncol 2009, 4:87-92.

12. Davies AM, Ruel C, Lara PN, Lau DH, Gumerlock PH, Bold R, Shibata S, Lenz $H J$, Schenkein DP, Gandara DR: The proteasome inhibitor bortezomib in combination with gemcitabine and carboplatin in advanced non-small cell lung cancer: a California Cancer Consortium Phase I study. J Thorac Oncol 2008, 3:68-74.

13. Escobar M, Velez M, Belalcazar A, Santos ES, Raez LE: The role of proteasome inhibition in nonsmall cell lung cancer. J Biomed Biotechnol 2011, 2011:806506

14. Fanucchi MP, Fossella FV, Belt R, Natale R, Fidias P, Carbone DP, Govindan R, Raez LE, Robert F, Ribeiro M, Akerley W, Kelly K, Limentani SA, Crawford J, Reimers HJ, Axelrod R, Kashala O, Sheng S, Schiller JH: Randomized phase II study of bortezomib alone and bortezomib in combination with docetaxel in previously treated advanced non-small-cell lung cancer. J Clin Oncol 2006, 24:5025-5033.

15. Lara PN Jr, Koczywas M, Quinn DI, Lenz HJ, Davies AM, Lau DH, Gumerlock PH, Longmate J, Doroshow JH, Schenkein D, Kashala O, Gandara DR: Bortezomib plus docetaxel in advanced non-small cell lung cancer and other solid tumors: a phase I California Cancer Consortium trial. J Thorac Oncol 2006, 1:126-134

16. Li T, Ho L, Piperdi B, Elrafei T, Camacho FJ, Rigas JR, Perez-Soler R, Gucalp R: Phase II study of the proteasome inhibitor bortezomib (PS-341, Velcade) in chemotherapy-naive patients with advanced stage non-small cell lung cancer (NSCLC). Lung Cancer 2010, 68:89-93.

17. Ryan DP, Appleman LJ, Lynch T, Supko JG, Fidias P, Clark JW, Fishman M, Zhu AX, Enzinger PC, Kashala O, Cusack J, Jr., Eder JP: Phase I clinical trial of bortezomib in combination with gemcitabine in patients with advanced solid tumors. Cancer 2006, 107:2482-2489.

18. Scagliotti GV, Germonpre P, Bosquee L, Vansteenkiste J, Gervais R, Planchard D, Reck M, De MF, Lee JS, Park K, Biesma B, Gans S, Ramlau R, Szczesna A, Makhson A, Manikhas G, Morgan B, Zhu Y, Chan KC, von PJ: A randomized phase II study of bortezomib and pemetrexed, in combination or alone, in patients with previously treated advanced non-small-cell lung cancer. Lung Cancer 2010, 68:420-426.

19. Lara PN Jr, Chansky K, Davies AM, Franklin WA, Gumerlock PH, Guaglianone PP, Atkins JN, Farneth N, Mack PC, Crowley JJ, Gandara DR: Bortezomib (PS-341) in relapsed or refractory extensive stage small cell lung cancer: a Southwest Oncology Group phase II trial (S0327). J Thorac Oncol 2006, 1:996-1001.

20. Bennett MK, Kirk CJ: Development of proteasome inhibitors in oncology and autoimmune diseases. Curr Opin Drug Discov Devel 2008, 11:616-625.

21. Demo SD, Kirk CJ, Aujay MA, Buchholz TJ, Dajee M, Ho MN, Jiang J, Laidig GJ, Lewis ER, Parlati F, Shenk KD, Smyth MS, Sun CM, Vallone MK, Woo TM, Molineaux CJ, Bennett MK: Antitumor activity of PR-171, a novel irreversible inhibitor of the proteasome. Cancer Res 2007, 67:6383-6391.

22. Kuhn DJ, Chen Q, Voorhees PM, Strader JS, Shenk KD, Sun CM, Demo SD, Bennett MK, van Leeuwen FW, Chanan-Khan AA, Orlowski RZ: Potent activity of carfilzomib, a novel, irreversible inhibitor of the ubiquitinproteasome pathway, against preclinical models of multiple myeloma. Blood 2007, 110:3281-3290.

23. Kupperman E, Lee EC, Cao Y, Bannerman B, Fitzgerald M, Berger A, Yu J, Yang Y, Hales P, Bruzzese F, Liu J, Blank J, Garcia K, Tsu C, Dick L, Fleming P, Yu L, Manfredi M, Rolfe M, Bolen J: Evaluation of the proteasome inhibitor MLN9708 in preclinical models of human cancer. Cancer Res 2010, 70:1970-1980.

24. Arastu-Kapur S, Anderl JL, Kraus M, Parlati F, Shenk KD, Lee SJ, Muchamuel T, Bennett MK, Driessen C, Ball AJ, Kirk CJ: Nonproteasomal targets of the proteasome inhibitors bortezomib and carfilzomib: a link to clinical adverse events. Clin Cancer Res 2011, 17:2734-2743.

25. Kuhn DJ, Hunsucker SA, Chen Q, Voorhees PM, Orlowski M, Orlowski RZ: Targeted inhibition of the immunoproteasome is a potent strategy against models of multiple myeloma that overcomes resistance to conventional drugs and nonspecific proteasome inhibitors. Blood 2009, 113:4667-4676.

26. Papadopoulos KP, Burris HA III, Gordon M, Lee P, Sausville EA, Rosen PJ, Patnaik A, Cutler RE Jr, Wang Z, Lee S, Jones SF, Infante JR: A phase I/II study of carfilzomib 2-10-min infusion in patients with advanced solid tumors. Cancer Chemother Pharmacol 2013, 72:861-868.

27. Siegel DS, Martin T, Wang M, Vij R, Jakubowiak AJ, Lonial S, Trudel S, Kukreti V, Bahlis N, Alsina M, Chanan-Khan A, Buadi F, Reu FJ, Somlo G, Zonder Song K, Stewart AK, Stadtmauer E, Kunkel L, Wear S, Wong AF, Orlowski RZ, Jagannath S: A phase 2 study of single-agent carfilzomib (PX-171-003-A1) in patients with relapsed and refractory multiple myeloma. Blood 2012, 120:2817-2825.

28. Vij R, Wang M, Kaufman JL, Lonial S, Jakubowiak AJ, Stewart AK, Kukreti V, Jagannath S, McDonagh KT, Alsina M, Bahlis NJ, Reu FJ, Gabrail NY, Belch A, Matous JV, Lee P, Rosen P, Sebag M, Vesole DH, Kunkel LA, Wear SM, Wong AF, Orlowski RZ, Siegel DS: An open-label, single-arm, phase 2 (PX-171-004) study of single-agent carfilzomib in bortezomib-naive patients with relapsed and/or refractory multiple myeloma. Blood 2012, 119:5661-5670.

29. Parlati F, Lee SJ, Aujay M, Suzuki E, Levitsky K, Lorens JB, Micklem DR, Ruurs $P$, Sylvain C, Lu Y, Shenk KD, Bennett MK: Carfilzomib can induce tumor cell death through selective inhibition of the chymotrypsin-like activity of the proteasome. Blood 2009, 114:3439-3447.

30. Andersson A, Fagerberg J, Lewensohn R, Ehrsson H: Pharmacokinetics of cisplatin and its monohydrated complex in humans. J Pharm Sci 1996, 85:824-827.

31. Chou TC, Talalay P: Analysis of combined drug effects - a New look at a very old problem. Trends Pharmacol Sci 1983, 4:450-454.

32. Zang Y, Thomas SM, Chan ET, Kirk CJ, Freilino ML, DeLancey HM, Grandis JR, Li C, Johnson DE: The next generation proteasome inhibitors carfilzomib and oprozomib activate prosurvival autophagy via induction of the unfolded protein response and ATF4. Autophagy 2012, 8:1873-1874.

33. Rotella V, Fornaro L, Vasile E, Tibaldi C, Boldrini L, Chella A, DI A, Cirigliano G, Chioni A, Lupi C, Sensi E, Ginocchi L, Giovannelli S, Pennucci M, Fontanini G, Baldini E: EGFR and K-Ras mutations in women with lung adenocarcinoma: implications for treatment strategy definition. J Exp Clin Cancer Res 2014, 33:77.

34. Yang Y, Ikezoe T, Saito T, Kobayashi M, Koeffler HP, Taguchi H: Proteasome inhibitor PS-341 induces growth arrest and apoptosis of non-small cell lung cancer cells via the JNK/c-Jun/AP-1 signaling. Cancer Sci 2004, 95:176-180.

35. Ling V: Multidrug resistance: molecular mechanisms and clinica relevance. Cancer Chemother Pharmacol 1997, 40(Suppl):S3-S8.

36. Wiberg K, Carlson K, Aleskog A, Larsson R, Nygren P, Lindhagen E: In vitro activity of bortezomib in cultures of patient tumour cells-potential utility in haematological malignancies. Med Oncol 2009, 26:193-201.

37. Ao L, Wu Y, Kim D, Jang ER, Kim K, Lee DM, Kim KB, Lee W: Development of peptide-based reversing agents for $P$-glycoprotein-mediated resistance to carfilzomib. Mol Pharm 2012, 9:2197-2205.

38. Galluzzi L, Senovilla L, Vitale I, Michels J, Martins I, Kepp O, Castedo M, Kroemer G: Molecular mechanisms of cisplatin resistance. Oncogene 2012, 31:1869-1883

39. Yang X, Wang J, Zhou Y, Wang Y, Wang S, Zhang W: Hsp70 promotes chemoresistance by blocking Bax mitochondrial translocation in ovarian cancer cells. Cancer Lett 2012, 321:137-143.

40. Ren JH, He WS, Nong L, Zhu QY, Hu K, Zhang RG, Huang LL, Zhu F, Wu G: Acquired cisplatin resistance in human lung adenocarcinoma cells is associated with enhanced autophagy. Cancer Biother Radiopharm 2010, 25:75-80.

41. de Wilt LH, Jansen G, Assaraf YG, Van MJ, Cloos J, Schimmer AD, Chan ET, Kirk CJ, Peters GJ, Kruyt FA: Proteasome-based mechanisms of intrinsic and acquired bortezomib resistance in non-small cell lung cancer. Biochem Pharmacol 2012, 83:207-217.

42. Kale AJ, Moore BS: Molecular mechanisms of acquired proteasome inhibitor resistance. J Med Chem 2012, 55:10317-10327.

43. Ling X, Calinski D, Chanan-Khan AA, Zhou M, Li F: Cancer cell sensitivity to bortezomib is associated with survivin expression and p53 status but not cancer cell types. J Exp Clin Cancer Res 2010, 29:8. 
44. Takayama K, Ogata K, Nakanishi Y, Yatsunami J, Kawasaki M, Hara N: Bcl-2 expression as a predictor of chemosensitivities and survival in small cell lung cancer. Cancer J Sci Am 1996, 2:212-216.

45. Mortenson MM, Schlieman MG, Virudachalam S, Lara PN, Gandara DG, Davies AM, Bold RJ: Reduction in BCL-2 levels by $26 \mathrm{~S}$ proteasome inhibition with bortezomib is associated with induction of apoptosis in small cell lung cancer. Lung Cancer 2005, 49:163-170.

46. Yang TM, Barbone D, Fennell DA, Broaddus VC: BCl-2 family proteins contribute to apoptotic resistance in lung cancer multicellular spheroids. Am J Respir Cell Mol Biol 2009, 41:14-23.

47. Zang Y, Thomas SM, Chan ET, Kirk CJ, Freilino ML, DeLancey HM, Grandis JR, Li C, Johnson DE: Carfilzomib and ONX 0912 inhibit cell survival and tumor growth of head and neck cancer and their activities are enhanced by suppression of Mcl-1 or autophagy. Clin Cancer Res 2012, 18:56395649.

48. Dasmahapatra G, Lembersky D, Son MP, Patel H, Peterson D, Attkisson E, Fisher RI, Friedberg JW, Dent P, Grant S: Obatoclax interacts synergistically with the irreversible proteasome inhibitor carfilzomib in GC- and ABC-DLBCL cells in vitro and in vivo. Mol Cancer Ther 2012, 11:1122-1132.

49. Wang Z, Yang J, Kirk C, Fang Y, Alsina M, Badros A, Papadopoulos K, Wong A, Woo T, Bomba D, Li J, Infante JR: Clinical pharmacokinetics, metabolism, and drug-drug interaction of carfilzomib. Drug Metab Dispos 2013, 41:230-237.

50. Lue J, Goel S, Mazumder A: Carfilzomib for the treatment of multiple myeloma. Drugs Today (Barc) 2013, 49:171-179.

\section{Submit your next manuscript to BioMed Central and take full advantage of:}

- Convenient online submission

- Thorough peer review

- No space constraints or color figure charges

- Immediate publication on acceptance

- Inclusion in PubMed, CAS, Scopus and Google Scholar

- Research which is freely available for redistribution 